\title{
ПЕРВАЯ СТЕПЕНЬ
}

\section{B.C. TOPMOШЕВA* \\ ГЛОБАЛЬНОЕ ПОЛИТИЧЕСКОЕ ПРОСТРАНСТВО В ПАРАДИГМЕ ПОСТМОДЕРНИЗМА}

Аннотация: Статья посвящена специфике постмодернистского взгляда на содержание характеристики «глобальное» по отношению к современному политическому пространству. Использовано характерное для постмодернистской методологии сочетание специальных подходов - транснационального, сетевого, акторного и коммуникативного. Предложены параметры для анализа современного политического пространства. Глобальное политическое пространство в парадигме постмодернизма описано как амбивалентное метафорическое понятие, характеризующее противоречивость мирового политического процесса в условиях глобализации: его единство и неоднородность, универсальность и плюралистичность, поступательность и дискретность, сочетание возможностей и ограничений.

Ключевые слова: глобализация; гражданское общество; политическая элита; политическое пространство; постмодернизм.

Для цитирования: Тормошева В.С. Глобальное политическое пространство в парадигме постмодернизма // Политическая наука. - М., 2019. - № 1. C. 206-224. - DOI: 10.31249/poln/2019.01.11

* Тормошева Вера Сергеевна, соискатель кафедры международных отношений и политологии Нижегородского государственного лингвистического университета (Нижний Новгород, Россия), e-mail: tormosh@mail.ru

Tormosheva Vera - postgraduate degree seeker of the International Relations and Political Science Department at Nizhny Novgorod Linguistics University (Nizhny Novgorod, Russia), e-mail: tormosh@mail.ru

(C) Тормошева B.C.

DOI: $10.31249 /$ poln/2019.01.11 


\section{V.S. Tormosheva \\ Global political space in the postmodern paradigm}

Abstract: The article examines the issue of the political space in the context of globalization. The focus is on the postmodern reconceptualization of the characteristic global when related to the modern political space. The study encompasses the typical for the postmodern methodology combination of special approaches, namely: transnational, communicative, network, and actor ones. New parameters for the modern political space analysis have been proposed. It is revealed that the postmodern paradigm articulates the global political space as an ambivalent metaphorical term, which characterizes the world political process inconsistency under the conditions of globalization: its integrity and irregularity, universality and adherence to pluralism, progressivity and discontinuity, a complex mix of opportunities and constraints.

Keywords: civil society; globalization; political elite; political space; postmodernism.

For citation: Tormosheva V.S. Global political space in the postmodern paradigm // Political science (RU). - M., 2019. - N 1 - P. 206-224. DOI: $10.31249 /$ poln/2019.01.11

В условиях глобализации на смену традиционным формам территориальной организации пространств приходят иные их разновидности. Наблюдающийся с середины прошлого века устойчивый интерес к проблематике политического пространства привел к появлению его новых интерпретаций - географической, социологической, антропологической и коммуникативной [Тормошева, 2016 , с. 1671. Несмотря на специфику каждого подхода, ученые единодушно характеризуют современное политическое пространство как «единое», или «общее». Понятие «глобальное» продолжает в этом плане синонимический ряд, построенный на идее единства и общности.

Данная статья посвящена постмодернистскому взгляду на политическое пространство и, в частности, на то, какое отражение в нем находят феномены информационного общества - дискретность и мозаичность.

\section{Основные подходы}

Проблематика современных научных дискуссий о политическом пространстве представлена несколькими тематическими бло- 
ками: что делает пространство политическим; смысл использования пространственных понятий в политических науках; формы осмысления политического пространства; возможность конструирования его универсальной ментальной карты; выбор параметров для его анализа; исследовательские направления в его изучении, характерные для эпохи глобализации; основные характеристики политического пространства в контексте политологического постмодерна.

Пространство не является однозначно политическим. Оно становится политическим, когда выступает средством формирования особых отношений к порядку вещей, выявления сегментов этого порядка и обеспечения построения политической идентичности. Чтобы приобрести политический смысл, пространство должно ассоциироваться с определенными позитивными или негативными изменениями в установленном порядке вещей, приводящими к новым отношениям, связям, либо разрывам и рассогласованиям, имеющим политическую значимость [Dikeç, 2012, p. 675].

В дискуссиях о политической сфере неизменно используются физические понятия «пространство», «направление», «позиция» и «дистанция» (например, высокая / низкая дистанция власти, позиции агентов политики по ключевым вопросам). Аналогия с физическим пространством более полувека признается достаточно плодотворной при рассмотрении политической проблематики, однако политические пространства остаются чисто концептуальными и не поддаются рассмотрению в географических параметрах [Benoit, Laver, 2012, p. 195]. Вне зависимости от исследовательского подхода «пространства» это, по сути, метафоры, и охватывающие их параметры и позиции агентов в данных параметрах недоступны наблюдению. Сложность методологического инструментария не может служить подтверждением того, что мы «правильно» охарактеризовали политическое пространство и «точно» поместили в него политических акторов, поскольку они не поддаются наблюдению, оставаясь метафорическими, а не физическими объектами [Ibid, p. 196].

Категория «политическое пространство» позволяет зафиксировать единство содержания и формы политического процесса в его мерном, пригодном к измерению абстрактном изображении. Политическое пространство осмысляется в форме моделей, алгоритмов, идеальных типизированных конструкций, стереотипов и архетипов [Цветкова, 2015, с. 8]. Исследователи используют не- 
сложные концептуальные карты-схемы политических пространств как удобный способ представить значительный объем политической информации, отбросив нерелевантные детали. При этом не существует как единственно правильной концептуальной карты какого-либо политического пространства, так и единственно верного концептуального пространственного параметра [Benoit, Laver, 2012, p. 215-216].

Анализируя политическое пространство, авторы опираются на различные атрибуты пространства или разнообразные формы пространственности [Dikeç, 2012, p. 675]. Традиционно мировое политическое пространство представляют в виде глобальной системы, состоящей из государств и их устойчивых блоков. Во внимание принимается то, что внутренняя структура каждого государства обладает региональными особенностями и «подразумевает серьезные различия между политическими интересами региональных и локальных сообществ в отношении к внешнему миру, другим государствам и вопросам внешней политики своего государства» [Туровский, 2011, с. 99].

Масштаб политического пространства может определяться иначе - к примеру, свободой слова, свободой собраний и правом на свободные и честные выборы [Internet freedom... 2013, p. 38]. В этом случае представления о политическом пространстве формируются благодаря степени реализации права устраивать митинги и образовывать ассоциации без вмешательства органов власти; права искать, получать и распространять информацию с использованием любых медиа вне зависимости от государственных границ; права партий и кандидатов на равные условия при проведении избирательной кампании [Ibid., p. 5]. Очевидно, что подобные параметры применимы при рассмотрении политического пространства национального государства.

Можно выделить два исследовательских направления в изучении политического пространства в условиях глобализации. Согласно первому, политическое пространство рассматривается как единое, общее и универсальное. Согласно второму, политическое пространство имеет дискретный, неоднородный и противоречивый характер.

Так, «единые / общие пространства» описывают отношения между странами СНГ и сотрудничество стран Евросоюза; Северная Америка и Западная Европа называются «прообразом единого политико- 
экономического пространства». Исследователи пишут о «взаимосвязанном политико-экономическом и социально-культурном пространстве Европы и Восточной Азии», «конструктивной, прогрессирующей общности» и расширении «единого и взаимосвязанного пространства политики, экономики и безопасности» [Тормошева, 2016, с. 169]. Развитие информационно-коммуникационных технологий и их использование в политической сфере приводит к тому, что «политическое пространство расширяется, уплотняется, становится все более однородным, способствуя формированию единого глобального пространства» [Плугатаренко, 2011, с. 136].

Однако наряду с упомянутой тенденцией к унификации и единообразию теоретики информационного общества отмечают антиномичную ей тенденцию дискретности, то есть прерывности глобальных и локальных процессов, мозаичности картины современного мира. Наиболее заметно эта дискретность акцентирована учеными-постмодернистами [Труевцев, 2012, с. 11].

В этом плане представляют интерес постмодернистские характеристики пространства. Пространство эпохи постмодерна метафора, объединяющая сферы деятельности, виды занятости, программы действий, имеющие свои границы подобно границам физического пространства. Это социальные конструкты, создающие ограничения или возможности участия в политике, экономике или общественной жизни. Понимание сущности пространства влияет на понимание деятельности индивидов и групп. Двухмерная интерпретация пространства сегодня теряет свою актуальность. Постмодернистское пространство многомерно, непостоянно и зависимо от обстоятельств. Следует говорить о множестве пространств - пересекающихся, совпадающих, существующих в отношениях противоречия или антагонизма. Пространство может интерпретироваться по-разному, иметь различные значения в разных обстоятельствах для разных участников [Rodgers, 2003, p. 8, 10-11].

\section{Методологические преимущества постмодернизма в изучении глобального политического пространства}

Данная статья продолжает переосмысление современного политического пространства в контексте постмодернизма. Наша задача - выяснить содержание характеристики «глобальное» в от- 
ношении формирующегося в процессе глобализации политического пространства, используя методологические достоинства постмодернизма.

К ним относят: признание права на существование различных концептуальных подходов, в том числе исключающих друг друга; уместность всякого рода интерпретативных различий, включая методологические; плюрализм подходов и ориентацию на их продуктивное взаимодействие; поиск совместимости и комплементарности элементов различных парадигм; возможность выхода политологического дискурса за пределы рационалистического знания эпохи модерна; свежий взгляд на политические реалии и открытие новых сфер политологического исследования; отрицание «универсальной истины» [Жуковский, 2011, с. 164-165, 169].

Следуя постмодернистской логике плюралистичности, множественности и междисциплинарности, настоящее исследование опирается на несколько научных подходов:

- транснациональныци - для акцентирования пространственного измерения политических процессов в условиях глобализации, изучения форм межкультурного взаимодействия поверх национальных, государственных, территориальных и политических границ, диагностирования сферы деятельности политического субъекта вне пределов национальной государственности, рассмотрения наднациональных уровней принятия и исполнения политических решений [Тормошева, 2017, с. 281];

- сетевой - для анализа внутренних структур политического пространства, представляющих собой пространственно распределенные сети горизонтальных взаимодействий с высокой степенью диффузии, тенденцией к распаду и повторному сочетанию в виде новой системы взаимодействия транснациональных акторов [Красина, 2010, с. 73];

- акторныци - при рассмотрении политического пространства как конструируемой реальности, внутри которой значимой является фигура актора, определяющего логику и характер развития этой реальности [там же, с. 74];

- коммуникативный - при изучении политического пространства как пространства политической коммуникации с преобладанием глобального английского языка, межкультурного политического дискурса как ведущей сферы общения, тенденции деформации смыслов в политической коммуникации информаци- 
онного общества, коммуникативных проблем на пересечении различных идеологий, мировоззрений и менталитетов [Юзефович, 2014, с. 51-66; Карпова, 2017, с. 18-26].

Выбор параметров для анализа современного политического пространства связан с вышеназванными исследовательскими подходами и преследует целью выявление специфики «глобальных» феноменов, а именно: глобальных информационно-коммуникационных сетей, глобальных политических акторов, средств осуществления глобальной политической коммуникации, глобальной мобильности и глобального политического процесса.

Такими параметрами, на наш взгляд, могут служить:

- наличие политико-коммуникативного единства;

- уровень глобальной мобильности;

- степень развития глобальной политической элиты;

- сформированность глобального гражданского общества;

- охват политической сферы языком международного общения.

\section{На пути к единому политическому пространству}

Как известно, политическое понимание глобализации связано с восприятием явлений общественной жизни через призму глобализма - «конгломерата воззрений, сводящегося в целом к подчеркиванию роли глобальных начал в жизни современного человечества и видящего в этих началах исключительно позитивное содержание» [Кулаков, 2011, с. 9]. Начнем со свидетельств влияния «глобальных начал» на формирование политического пространства и динамику этого процесса.

Во-первых, объединяющим началом сложностей и противоречий глобального мира выступает информационно-коммуникационная составляющая.

«Сеть» - ключевой термин глобализации, в равной степени применимый к межконтинентальному распространению телекоммуникации, массового туризма и массовой культуры, трансграничным рискам крупных предприятий, торговле оружием, экологическим воздействиям мирового масштаба, международному сотрудничеству правительственных или неправительственных организаций [Хабермас, 2005, с. 279-280]. Не случайно сетевую мо- 
дель называют одной из организационных форм участия ассоциативных (конфессиональных, этнических, деловых и др.) и неассоциативных групп интересов в глобальных процессах и внешней политике [Туровский, 2011, с. 105].

Сети играют важную роль в формировании идеологического сектора глобального сообщества, поскольку являются инструментом актуализации локальных проблем и их продвижения на глобальный уровень международного обсуждения. Другими словами, происходит становление повестки дня мировой политики, «находящейся "по ту сторону” традиционной проблематики межгосударственных взаимодействий и обладающей глобальным по охвату форматом» [Мельвиль, 2004, с. 107].

Одним из главных сетевых эффектов является существенное снижение значения вертикальных связей при одновременном усилении роли горизонтальных. В политической практике это означает вызов иерархически организованным политическим структурам - в первую очередь государствам и политическим партиям [Труевцев, 2012 , с. 26]. В современном мире традиционная иерархическая модель управления претерпела значительные изменения в пользу смешения традиционных, новых и гибридных процессов на самых разных уровнях: локальном, национальном, наднациональном. Индивиды с легкостью становятся членами международных сетей, минуя посредничество национальных институтов; небольшие локальные группы напрямую взаимодействуют с транснациональными структурами; региональные объединения вступают в партнерские связи за рубежом без вмешательства соответствующих государств [Anderson, 1996, p. 150].

Через взаимодействие и противодействие национальных, региональных, религиозных или профессиональных сетей солидарности создаются новые массовые формы политического участия, например транснациональный интернет-активизм. Возможности Интернета дают свободу самовыражения, позволяют оперативно выражать мнение, создавать и размещать политическую информацию онлайн в различных форматах, охватывая практически неограниченную аудиторию [Internet freedom... 2013, p. 6]. Подобные формы уже оказывают влияние на политическую систему и формирование политического пространства [Rodgers, 2003, p. 137138]: видоизменяются пространственные детерминанты политического сообщества; политические интеракции приобретают много- 
уровневый характер; снижается важность физической территории как хранилища политического значения; расширяются возможности индивидов в получении доступа к информации; гегемония определенного политического актора сменяется сетевым равенством множества политических акторов; государство утрачивает способность полностью контролировать дискурсивные практики публичной сферы.

Во-вторых, одним из проявлений глобализации признают усиление пространственной подвижности населения и вовлечение все большего количества граждан в процессы международной миграции. Основная масса исследований глобализации посвящена открытости и проницаемости границ. Текучесть, динамичность, мобильность глобального пространства признаются его прогрессивными характеристиками. Такие явления, как глобальные интеракции и глобальная мобильность, ассоциируются в современной общественной мысли с идеей единства и общности.

Говорить о глобальных интеракциях, хотя и в самом общем смысле, позволяет активное движение информации, финансов, физических объектов, людей и других материальных и нематериальных единиц через государственные границы. К их основным видам относят: коммуникацию (движение информации, распространение убеждений, идей и установок); транспортное сообщение (движение физических объектов - военного имущества, личной собственности, коммерческих грузов); финансовую деятельность (движение денежно-кредитных средств); перемещение лии (путешествия, деловые поездки) 「Keohane, Nye, 1971, p. 332†. При этом международная деятельность может включать все виды глобальных интеракций, требуя координации информационных, финансовых, человеческих потоков и физических ресурсов.

Так называемая глобальная мобильность является в современном мире базовой характеристикой человеческого существования [Сизиков, 2005, с. 88]. Сторонники позитивного влияния глобализации утверждают, что пространство утрачивает сковывающее влияние на глобально мобильных личностей, добровольных участников межкультурного взаимодействия. Мобильным личностям приписывается легкость адаптации к новым условиям: пространственным, темпоральным, информационным, культурным, идеологическим [там же, с. 100-101, 114-115]. 
В-третьих, формированию глобального политического пространства способствует становление глобальной политической элиты. На смену элитам, образованным по национально-государственному признаку, приходят глобальные элиты [Брега, Копылов, 2014, с. 78]. Образ жизни политической и экономической элит в различных странах становится ближе друг к другу, все более отделяясь от проблем местного населения [Кулаков, 2011, с. 13]. Представители этого круга являются носителями и проводниками глобальных воззрений на мировой политической арене. Продвижение идеологии глобализма и глобалистских инициатив выступает опорой власти и источником ресурсов элиты [Тормошева, 2017, с. 282].

Интенсивная мобильность, космополитический образ жизни, высокие доходы и развитое классовое самосознание обеспечивают переход международной элиты к глобальному управлению и принятию решений на наднациональном уровне. Находящиеся в ее руках ресурсы предоставляют практически неограниченные возможности для проведения нужной политики и последовательного устранения всяческих препятствий, включая смену политической власти в стране, где интересы национальной элиты расходятся с интересами элиты глобальной [Брега, Копылов, 2014, с. 81-82].

В-четвертых, формируется глобальное гражданское общество. Впервые этот термин стали использовать в контексте деятельности Организации Объединенных Наций. Достижение глобальных целей борьба с несправедливостью, повышение безопасности человечества, создание более гармоничного миропорядка и усиление влияния стран Юга в глобальной полемике - по мнению $\mathrm{OOH}$, возможно путем налаживания продуктивного взаимодействия с гражданским обществом в глобальном масштабе [Канунников, 2017, с. 297]. Данная сфера моделируется деятельностью различного рода неправительственных организаций по всему спектру международной правозащитной проблематики, вопросам содействия демократическим преобразованиям, экологическим проблемам и пр. [Мельвиль, 2004, с. 107].

Конкретизируя разницу между гражданским обществом и глобальным гражданским обществом [Lipschutz, 2000, p. 18], отметим, что гражданское общество включает политические, культурные и общественные организации современного общества, автономные от государства, но регулирующие отношения между государством и обществом. В свою очередь, глобальное гражданское общество формируется как результат деятельности локаль- 
ных, национальных и международных неправительственных организаций по множеству вопросов: защита мира, окружающей среды, угнетенных слоев населения, граждан с умственными и физическими нарушениями, бездомных, прав животных, людей нетрадиционной сексуальной ориентации, национализм, популизм, феминизм, анархизм, синтетические религиозные культы, политические процессы в развивающихся странах и др. Несмотря на все разнообразие, эти движения объединены поисками нового политического выражения и нового пространства для политических действий [Rosenau, 1992, p. 144-147].

Очевидно, что негосударственные субъекты играют все более важную роль в обществе и управлении, в том числе на глобальном уровне. Организации гражданского общества через самые различные медиаканалы информируют граждан о вариантах решения определенных проблем в той или иной сфере жизни общества. Глобальные объединения активистов, парламентариев, журналистов, лидеров общественных движений оказывают влияние на обсуждение проблем политики, особенно международных вопросов. Фактически мы наблюдаем новое явление - формирование мирового общественного мнения, которое определяет политическую повестку дня и обозначает комплекс норм и гражданских требований, выходящих за пределы национальных границ [Канунников, 2017, c. 299].

В-пятых, современные общественно-политические процессы осуществляются в культурно и лингвистически обусловленном пространстве, которое не может обойтись без языка всемирного общения. Таким lingua franca сегодня выступает глобальный английский. В политической сфере наблюдается новый тип дискурса, объединяющий национальные политические дискурсы многих стран, - межкультурный политический дискурс. Этот тип дискурса формируется в условиях глобального коммуникативного пространства и реализуется в международных, межнациональных, межгосударственных и транснациональных объединениях [Юзефович, 2014, с. 55]. Он обладает потенциальными возможностями выражения идентичности доступным для большинства языком глобальным английским - и согласования множества политических позиций. 


\section{Глобальное политическое пространство не значит единое?}

В то же время современное политическое пространство выступает носителем характеристик, не позволяющих считать его единым и универсальным.

Во-первых, следует усомниться в политико-коммуникативном единстве глобального пространства. Напомним главное противоречие эпохи постмодерна: политическая глобализация не соответствует экономической. Мировое хозяйство, сформировавшиеся информационное и экологическое пространства не привели к появлению адекватных глобальному миру интеграционных политических процессов. Современные международные структуры не в состоянии выполнить функцию управления глобальным миром. Мировое сообщество национальных государств многополярно по характеру. В свою очередь, эффективность глобального управления предполагает опору на общую систему основополагающих ценностей, общечеловеческую мораль и дееспособное глобальное право [Абылгазиев, Ильин, 2009, с. 53-54].

Культурные различия, сложившееся тяготение государств к определенному типу политического устройства, сильное влияние идеологии и религии не позволяют говорить о перспективе создания глобального политического пространства. В то время как экономика, торговля, средства коммуникации и культура становятся более глобальными по своему характеру, представительная демократия по существу остается национальной и локальной. Политика в глобальном масштабе отстает от экономики: принимаемые на международном уровне решения требуют разработки прочной демократической основы для глобального управления, т.е. подотчетности гражданам [Канунников, 2017, с. 298].

Исключением следует признать опыт Европейского союза, представляющего собой наднациональное, надстрановое, региональное объединение, где интеграционный процесс принял торгово-экономический и политический характер. Сегодня ЕС - достаточно гомогенная экономико-политическая структура с единой законодательной и складывающейся исполнительной властью, едиными границами, расширяющейся зоной единой паспортной и валютной системы [Труевцев, 2012, с. 18]. О перспективах создания единого политико-коммуникативного глобального пространства говорить рано, если вообще возможно. 
Во-вторых, помимо интеграционных явлений, вроде описанной выше глобальной мобильности, имеет место и нулевая мобильность [Сизиков, 2005, с. 88-115]. Определяемая как локальная скованность, крайне низкая или нулевая степень реальной и виртуальной мобильности затрудняет международные миграции. Назовем такие «барьеры» свободного передвижения, как финансовые проблемы, отсутствие IT-компетенций, невладение иностранными языками, в частности английским. К примеру, так называемые нерегулярные интернет-пользователи, составляющие в некоторых странах подавляющее большинство, немобильны в плане поиска, получения, размещения и распространения политической информации [Internet freedom... 2013, p. 6].

Подобные проблемы приводят к тому, что люди находятся на периферии глобального пространства, вынужденно привязаны к территории, и связь с пространством может восприниматься как непреодолимое препятствие.

В-третьих, несмотря на процесс формирования глобальной элиты, ее не следует рассматривать как элиту исключительно политическую. Межкультурные процессы в большей степени охватили деловую элиту - представителей финансовой, телекоммуникационной и энергетической отраслей, интеллектуальную и культурную элиты, элиты спецслужб, организованной преступности и других функциональных сегментов. Кроме того, глобальная элита слабо развита институционально - отсутствуют структуры, которые можно было хотя бы приблизительно уподобить «мировому правительству» ГБрега, Копылов, 2014, с. 79-801.

Добавим, что в условиях снижения роли национального государства, изменения представлений об управляемости политической ситуацией у элиты усиливается чувство нестабильности и неуверенности. Ее решениям присуща ослабленная ответственность, они плохо поддаются парламентскому и гражданскому контролю, не обеспечивают баланс между преимуществами экономической глобализации и социальной справедливостью, между «включенностью» в международные процессы и сохранением приоритетности национальных интересов [Кулаков, 2011, с. 13].

В-четвертых, исследования показывают, что глобальное гражданское общество пока еще далеко от планетарного охвата.

Экспертные оценки проектной активности ООН и опыта глобальных протестных движений позволяют говорить о глобаль- 
ном гражданском обществе как о множественности гражданских обществ отдельных стран с выходом на высокий уровень интернационализации [Канунников, 2017, с. 310, 315]. Для них характерен новый тип солидарности - маневренная солидарность: ситуативное создание кратковременных неустойчивых связей по актуальному политическому поводу. При таком типе солидарности не выстраиваются прочные формально-структурные взаимосвязи с долговременной перспективой [Карпова, 2017, с. 19, 24].

Слаженности политических действий гражданского общества мешают ограничения, связанные с уровнем распространения Интернета и спецификой политических режимов [Internet freedom... 2013 , p. 39-40]. Чем большим ограничениям подвергается интернет-сфера, тем проблематичнее политическая онлайн-мобилизация аудитории. Велика вероятность рассогласования между зародившимся онлайн-движением и пониманием его сущности гражданами, чей доступ к Интернету ограничен. В результате политический нарратив не находит достаточного отклика среди аудитории.

Специфика политического режима влияет на трансформации онлайн-мобилизации в политическом пространстве в конкретные офлайн-стратегии. К примеру, характерная для авторитарных режимов блокировка политических партий, групп интересов и гражданского общества лишает онлайн-активистов политической опоры для запуска офлайн-мобилизации. Жесткая государственная цензура СМИ либо полностью блокирует освещение событий, что могло бы вызвать онлайн-дискуссии, либо задает рамки, сужающие дискуссионный потенциал. Фильтрация онлайн-трафика властями препятствует получению лидерами общественного мнения необходимой информации и инициированию политической дискуссии среди интернет-пользователей; репрессивные меры значительно ограничивают выражение политической воли и организацию коллективных действий.

Все эти ограничения делают взаимосвязь между онлайн- и офлайн-мобилизацией неустойчивой, а политические действия спонтанными. Как следствие, становление глобального гражданского общества происходит несимметрично.

В-пятых, эффективность общения в рамках глобального пространства осложняется проблемами коммуникативного характера. Так, глобальное распространение получила информационная аномия - непрерывный процесс производства информационных 
ошибок, погрешностей, дефектов во всех элементах коммуникативной цепи. При информационном общении посредством средств массовой коммуникации нередко смысл искажается, замещается или вовсе теряется, в результате чего создается множественность вариантов понимания, имитация реального смысла и иллюзия реальности у массовой аудитории [Карпова, 2017, с. 37]. Складывающееся на этом фоне общественное мнение мирового сообщества представляет собой «нечто сомнительного происхождения, безликое и безответственное, но, тем не менее, воздействующее на умы и сердца людей» [Кулаков, 2011, с. 14].

Аномия в поле публичной политической коммуникации проявляет себя в виде неспособности массового сознания граждан адекватно реагировать на неконтролируемый поток информации и делать обоснованный выбор; в неготовности граждан в условиях социального, экономического, политического кризиса принимать и усваивать новые правила социальной жизни; в отсутствии гражданской инициативы. В такой политической коммуникации происходит рассогласование участников коммуникативного процесса и не принимаются коллективно-обязательные решения [Карпова, 2017 , с. $21,25,40]$.

Современное пространство коммуникации для участника глобальных интеракций является «иным» локусом по сравнению с привычным и предполагает столкновение с другой культурой, другими социальными нормами и моделями поведения [Красина, 2010 , с. 72]. В глобальном коммуникативном пространстве пересекаются различные идеологии, менталитеты, мировоззрения, а также прагматические интенции индивида, который может стремиться к точности и объективности передачи информации, или, напротив, к ее искажению [Юзефович, 2014, с. 52, 72].

Объективные сложности формирования глобального коммуникативного пространства включают: мультикультурность политического дискурса; практически неограниченное увеличение объема информации; концептуальную и понятийную неоднозначность языковых средств; отражающиеся в политическом лексиконе изменения экономической и общественно-политической ситуации; проблемы с доступностью политической терминологии и языковых средств [там же, с. 75-76]. В рамках глобального межкультурного политического дискурса англоязычное описание политической картины мира проявляется через призму «чужого» языка, что 
так или иначе деформирует политическую картину мира. Как следствие, исследователи отмечают невозможность гармонизации в ближайшей перспективе политического дискурса при контакте идеологически разных лингвокультур [Юзефович, 2014, с. 396].

\section{Подводя итоги}

Несмотря на все аргументы в пользу становления глобального политического пространства, последнее пока не может быть охарактеризовано как единое или общее. Культурные, исторические, религиозные, идеологические различия не препятствуют экономической глобализации, но делают невозможным построение аналогичного политического пространства, основанного на универсальных ценностях. Логика его формирования нестабильна, склонна к быстрой изменчивости и вариативности, не имеет доминирующего стандарта развития и сочетает множество противоречивых технологий.

Глобальное политическое пространство в парадигме постмодернизма - амбивалентное метафорическое понятие, характеризующее противоречивость мирового политического процесса в условиях глобализации: его единство и неоднородность, универсальность и плюралистичность, поступательность и дискретность, сочетание возможностей и ограничений.

С одной стороны, динамичное распространение глобальных интеракций, появление новых каналов и инструментов глобальных взаимодействий участников мировой политики, сетевая организация участия многочисленных групп интересов в глобальных процессах позволяют практически беспрепятственно преодолевать любые границы и отражают тенденцию к политико-коммуникативному единству. С другой стороны, многополярность мирового сообщества, представленного национальными государствами, привносит в пространство политико-коммуникативные разрывы.

Наряду с процессами глобальной мобильности, способствующей адаптации к современным пространственным, темпоральным, информационным, культурным и идеологическим условиям, имеет место локальная скованность, т.е. крайне низкая или нулевая степень реальной и виртуальной мобильности. Финансовые проблемы, отсутствие IT-компетенций, невладение иностранными 
языками, в частности глобальным английским, - все это препятствует интеграции граждан в мировой политический процесс, оставляет их на периферии политического пространства.

Глобальная элита имеет преимущественно деловой, а не политический характер. Политическая элита, в свою очередь, слабо развита институционально, в ее составе отсутствуют структуры, подобные мировому правительству, а ее решения отличаются нестабильностью, неуверенностью, недостаточной ответственностью, неспособностью обеспечить баланс между экономическими выгодами глобализации и социальными потребностями гражданского общества.

Глобальное гражданское общество складывается из интернационализации деятельности множества локальных, национальных и международных неправительственных движений. Их политическая солидарность ситуативна, краткосрочна и неустойчива. Слаженность политических действий зависит от разновидности политического режима и возможностей доступа к Интернету. Наиболее уязвима политическая активность локального уровня в условиях авторитарных режимов с их жесткой государственной цензурой традиционных и новых медиа, блокировкой оппозиционных партий и общественных движений, репрессиями в отношении граждан, открыто проявляющих свою политическую волю.

Несмотря на распространение глобального английского языка в качестве lingua franca, политической сферы объединения национальных политических дискурсов до сих пор не произошло. Гармонизации международного политического дискурса препятствует идеологическое несоответствие многочисленных лингвокультур, а также масштабные последствия информационной аномии, что приводит к коммуникативной рассогласованности участников мирового политического процесса.

\section{Список литературы}

Абылгазиев И.И., Ильин И.В. Процессы глобализации и проблема нового мироустройства // Век глобализации. - Волгоград, 2009. - № 2. - С. 40-60.

Брега А.В., Копылов И.А. Транснационализация политической элиты и влияние этого процесса на снижение национального суверенитета // Власть. - М., 2014. № 11. - C. $77-83$. 
Жуковский А.Г. Модели взаимодействия постмодернизма с другими методологиями в исследовании политических процессов // Государственное и муниципальное управление: Ученые записки СКАГС. - Ростов/н-Д, 2011. - № 4. C. $163-170$.

Канунников А.А. Гражданское общество в условиях европейского интеграционного процесса: Дис. ... д-ра полит. наук. - М., 2017. - 441 с.

Карпова А.Ю. Информационная аномия в политической коммуникации: Автореф. дис. ... д-ра соц. наук. - М., 2017. - 46 с.

Красина О.B. Конструирование транснационального пространства как теоретикометодологическая проблема в современной теории мировой политики // Власть. М., 2010. - № 11. - С. 69-74.

Кулаков А.В. Политическая и культурная глобализация: Два измерения многомерного процесса. Ч. 1: Политико-экономическое пространство глобализации // Пространство и время. - М., 2011. - № 1 (3). - С. 8-18.

Мельвиль А.Ю. Становление транснациональной политической среды и «волны» демократизации // Современные международные отношения и мировая политика / Отв. ред. А.В. Торкунов. - М.: Просвещение, 2004. - С. 106-142.

Плугатаренко П.Н. Проблема исследования политического пространства в условиях глобализации // Вестник МГОУ. История и политические науки. - М., 2011. - № 1. - C. 135-137.

Сизиков А.A. Динамика формирования транснационального культурного пространства в контексте глобализации: Дис. ... канд. культ. наук. - СПб., 2005. $182 \mathrm{c}$.

Тормошева B.C. Акторы современного политического пространства в контексте транснационализации // Вестник ТГУ. Философия. Социология. Политология. Томск, 2017. - № 37. - С. 280-290.

Тормошева В.С. Современные подходы к интерпретации политического пространства // Вестник Поволжского института управления. - Саратов, 2016. № 6 (57). - C. 167-173.

Труевцев К.М. Глобализация как политический процесс: Препринт WP14/2012/06. М.: Изд. дом Высшей школы экономики, 2012. - 36 с.

Туровский Р.Ф. Субнациональные регионы в глобальной политике (на примере России) // Полис. Политические исследования. - М., 2011. - № 2. - С. 99-117.

Хабермас Ю. Постнациональная констелляция и будущее демократии // Политические работы. - М.: Праксис, 2005. - С. 269-340.

Цветкова О.В. Политическая лимология: Концепт границы // РЕГИОНОЛОГИЯ = REGIONOLOGY. - Саранск, 2015. - № 3 (92). - C. 5-13.

Юзефович Н.Г. Адаптация английского языка в межкультурном политическом дискурсе «Россия - Запад»: Дис. ... д-ра филол. наук. - СПб., 2014. - 596 с.

Anderson $J$. The shifting stage of politics: new medieval and postmodern territorialities? // Environment and planning D: Society and space. - L., 1996. - Vol. 14 (2). P. 133-153.

Benoit K., Laver M. The dimensionality of political space: Epistemological and methodological considerations // European Union politics. - Oxford: Oxford univ. press, 2012. - Vol. 13, N 2. - P. 194-218. 
Dikeç M. Space as a mode of political thinking // Geoforum. - Amsterdam, 2012. Vol. 43. - P. 669-676.

Internet freedom and political space / O. Tkacheva, L.H. Schwartz, M.C. Libicki, J.E. Taylor, J. Martini, C. Baxter. - Santa Monica, CA: RAND, 2013. - 286 p.

Keohane R.O., Nye J.S. Transnational relations and world politics: An introduction // International organization. - Cambridge: Cambridge univ. press, 1971. - Vol. 25, N 3. - P. 329-349.

Lipschutz R.D. Crossing borders: Global civil society and the reconfiguration of transnational political space // GeoJournal. - Berlin, 2000. - Vol. 52, N 1. - P. 17-23.

Rodgers $J$. Spatializing international politics: Analysing activism on the internet. - L.: Routledge, 2003. - $184 \mathrm{p}$.

Rosenau P.M. Post-modernism and the social sciences: Insights, inroads, and intrusions. - Princeton, N.J.: Princeton univ. press, 1992. -248 p. 